\title{
Prelúdios das proposições para a Filosofia na Reforma do Ensino Médio em Santa Catarina
}

\author{
Preludes to the propositions for Philosophy in the Secondary Education \\ Reform in Santa Catarina.
}

\author{
Gilberto Oliari \\ Professor doutor da Universidade Comunitária da Região de Chapecó, Chapecó, \\ SC, Brasil. \\ gilba@unochapeco.edu.br - https://orcid.org/0000-0003-3102-8383
}

Recebido em 25 de agosto de 2021

Aprovado em 08 de novembro de 2021

Publicado em 30 de dezembro de 2021

RESUMO: O presente artigo tem como objetivo sistematizar e apresentar o processo inicial de constituição da Base Curricular do Ensino Médio do Território Catarinense, proposto a partir da reforma dessa etapa da Educação Básica. Nesse sentido, busca-se expor alguns encaminhamentos realizados pela Secretaria de Estado da Educação de Santa Catarina - SED/SC, referentes a construção e disponibilização para consulta pública do documento intitulado 'Marco Zero: Currículo Base do Ensino Médio do Território Catarinense'. Além disso, sistematiza-se algumas inspirações gerais para a Filosofia, bem como objetos do conhecimento e as habilidades trazidas no respectivo 'Marco Zero', no tocante ao ensino de Filosofia. Conclui-se problematizando o alinhamento dessa proposição curricular com a Base Nacional Comum Curricular - Ensino Médio.

Palavras-chave: Ensino de Filosofia; Reforma do Ensino Médio; Santa Catarina; Currículo; Base do Território Catarinense.

ABSTRACT: This article aims to systematize and present the initial process of constitution of the Curriculum Base for Secondary Education in the Territory of Santa Catarina, proposed from the reform of this stage of Basic Education. In this sense, we seek to expose some steps taken by the Secretary of State for Educations of Santa Catarina - SED/SC, regarding the construction and availability for public consultation of the document entitled 'Machine Zero: Basic Curriculum of High School in the Territory of Santa Catarina'. In addiction, some general inspirations for Philosophy are systematized, as well as objects of knowledge and the skills brought in the respective 'Ground Zero', regarding the teaching of Philosophy. It concludes by questioning the alignment of this curricular proposition with the Common National Curriculum Base - High School.

Keywords: Teaching of Philosophy; High School; Reform; Santa Catarina; Base of the Territory of Santa Catarina. 


\section{Considerações iniciais}

A reforma do Ensino Médio, tocante à lei 13.415/2017 (BRASIL, 2017), no Estado de Santa Catarina, vem sendo implementada desde o ano de dois mil e dezenove (2019), em cento e vinte (120) escolas-piloto (SILVA, MARTINI, POSSAMAI, 2021). Isso demonstra que esse Estado buscou estar alinhado às proposições de implementações de reformas deferidas pelo Ministério da Educação brasileiro. Uma informação relevante, apresentado pelas autoras acima referenciadas é que "[...] ao final de 2019, as escolas-piloto possuíam acesso apenas ao currículo da matriz da primeira série do Ensino Médio liberado para consulta" (SILVA, MARTINI, POSSAMAI, 2021, p. 71), o que demonstra que a grande preocupação da Secretaria de Estado da Educação de Santa Catarina, foi implementar o Novo Ensino Médio, sem possuir a definição completa do currículo (ou dos princípios curriculares que apontaria para essa etapa da educação).

Nessa tangente, a proposição curricular inicial da Secretaria de Estado da Educação de Santa Catarina - SED/SC foi relativa às disciplinas eletivas, relegando a segundo plano os componentes curriculares obrigatórios (componentes de formação geral básica) que demandavam revisão para alinhamento à Base Nacional Comum Curricular. Assim, a SED/SC firmou parceria com o Instituto lungo, o qual, de modo gratuito, ofertou formação de professores para a articulação e construção das ementas das disciplinas eletivas ao longo do ano de dois mil e vinte (2020) (SILVA, MARTINI, POSSAMAI, 2021).

Considerando essas questões apontadas pelas pesquisadoras acima, é válido tratar do documento: 'Caderno de orientações para a implementação do Novo Ensino Médio' (produzido e divulgado pela Secretaria de Estado da Educação no ano de dois mil e dezenove - 2019 a). Esse documento apresentava algumas diretrizes, as quais as escolas deveriam seguir no planejamento e execução da implementação da reforma do Ensino Médio. Na proposição curricular, o documento indicava a presença de componentes curriculares voltados à formação geral básica e itinerários formativos. A Filosofia, estava descrita nesse documento, como componente curricular integrado à área de Ciências Humanas e Sociais Aplicadas 
(na formação geral básica), com carga horária definida (sempre com uma aula de quarenta e cinco minutos nos três anos do Ensino Médio) (SANTA CATARINA, 2019 a).

Com a implementação da reforma do Ensino Médio ocorrendo no cenário nacional, era necessário desenvolver um currículo próprio no Estado. Essa construção se fazia necessária levando em consideração que Estados e municípios propõem seus currículos integrados, levando em conta o regime de colaboração que prevê adequações curriculares nos diferentes entes federativos para a execução dos planos educacionais.

Por fazer parte da direção de uma escola da referida rede, tive a oportunidade de acompanhar alguns movimentos da Secretaria de Estado da Educação. Um deles se refere à construção e disponibilização para consulta pública do documento intitulado 'Marco Zero: Currículo Base do Ensino Médio do Território Catarinense'. Ele se apresentava como um esboço intencional de como seria a proposição curricular da rede estadual para o Ensino Médio. Este 'Marco Zero' foi produzido por cinco redatores (três professores especialistas e dois mestres), sob supervisão de uma coordenadora de área (professora doutora) e disponibilizado para consulta pública no mês de janeiro do ano de dois mil e vinte (2020).

O presente artigo tem como objetivo sistematizar e refletir sobre o modo como o Estado de Santa Catarina apresentou o 'Marco Zero' do Currículo Base do Ensino Médio do Território Catarinense, proposto a partir da reforma do Ensino Médio, atento às indicações relativas à presença da Filosofia nesse processo. Nessa esteira, a pergunta que movimenta essa sistematização é: qual a incidência curricular da Filosofia no processo de reforma do Ensino Médio no Estado de Santa Catarina?

Desse modo, busquei pesquisar nos sítios eletrônicos da Secretaria de Estado da Educação e do Conselho Estadual de Educação - ambos de Santa Catarina, matérias jornalísticas e documentos que contribuíssem com essa sistematização produzida. Além disso, estivemos atentos aos movimentos do Conselho Estadual de Educação, no que tange a aprovação e implementação desse novo arranjo curricular, pertinente à reforma do Ensino Médio no Estado. Assim, 
tracei um percurso que possibilita ao leitor perceber os diferentes momentos históricos do currículo do Estado, chegando à proposição curricular para a efetivação da reforma curricular do Ensino Médio.

\section{Emergência do Currículo Base do Território Catarinense do Ensino Médio}

É preciso iniciar essa reflexão contextualizando que, o Estado de Santa Catarina, desde muitos anos possui/possuía uma proposta curricular, a qual indicava o percurso pedagógico que as escolas do Estado deveriam se inspirar para desenvolver suas ações pedagógicas. A última atualização da Proposta Curricular de Santa Catarina - PCSC, aconteceu no ano de dois mil e quatorze (2014). Naquela atualização, realizada de modo democrático com a participação efetiva (presencial) dos professores e consultores das escolas da rede, propôs-se a noção de percurso formativo e de diversidade como princípio formativo como balizadores de seu constructo.

Além disso, a referida proposta buscava apontar contribuições das áreas do conhecimento para a educação básica e para a formação integral, elencando um conjunto de conceitos articuladores dos componentes curriculares dentro das áreas do conhecimento. Naquele documento, não havia a indicação do desenvolvimento de habilidades e competências, nem de conteúdos específicos; apresentava-se um conjunto de conceitos que possibilitava os/as professores/as planejarem e executarem suas ações pedagógicas. Assim, a PCSC (2014) delineava a pertinência da Filosofia no Ensino Médio, considerando a importância do acesso aos conhecimentos produzidos pelos filósofos, os quais possibilitariam aos estudantes o desenvolvimento de atitudes comunicativas, críticas, alteritárias, dialógicas etc. (SANTA CATARINA, 2014, p. 147).

Conforme citado no início deste artigo, no ano de dois mil e dezessete (2017) o Ministério da Educação propôs (inicialmente, através de uma medida provisória, sem debate com instituições e entidades educacionais) uma reforma para o Ensino Médio (BRASIL, Lei 13.415/2017). Santa Catarina, através de sua rede de educação tratou de planejar e implementar a referida proposta de reforma, levando em 
consideração os prelúdios curriculares apontados pela Base Nacional Comum Curricular - BNCC (2018), que foi promulgada par e passo a reforma. Logo que a BNCC foi homologada, percebeu-se uma incompatibilidade entre ela e a Proposta Curricular de Santa Catarina (2014), o que desafiou o Estado a produzir seu currículo territorial, alinhado à BNCC.

No ano de dois mil e dezenove (2019), o Estado publicou o Currículo Base da Educação Infantil e do Ensino Fundamental do Território Catarinense, em grande medida alinhado à BNCC dessas etapas da Educação Básica, no entanto apresentando suas particularidades (este documento foi construído e avaliado de modo participativo com envolvimento de professores de todas as regiões do Estado). Dentre as particularidades, apontamos que a diversidade como princípio formativo continuou vigorando como caminho condutor para as ações pedagógicas do Estado, apontando 7 eixos para seu desenvolvimento: Educação ambiental formal; educação para as relações étnico-raciais; educação de pessoas jovens, adultas e idosas EJA; educação escolar quilombola; educação escolar indígena; educação do campo; educação especial na perspectiva da educação inclusiva.

Buscando a construção e a proposição de um currículo para o Ensino Médio, no dia vinte e sete (27) de janeiro do ano de dois mil e vinte (2020), através do Ofício Circular número zero oito (08), a Secretaria de Estado da Educação de Santa Catarina, encaminhou às escolas um documento intitulado de 'Marco Zero do Currículo Base do Ensino Médio do território Catarinense'. De acordo com o ofício circular (SED 08/2020), estava sendo disponibilizado para conhecimento e participação da sociedade um documento que havia sido construído por um "grupo de redatores formadores do Ensino Médio das Áreas do conhecimento da Secretaria do Estado da Educação de Santa Catarina (SED) e da União de Dirigentes Municipais (UNDIME)" (SED, 2020). Esse documento era o início da construção do Currículo Base do Território Catarinense - Ensino Médio.

Abaixo, na imagem 1, podemos visualizar o convite que a Secretaria de Estado da Educação faz à população para a consulta pública do 'Marco Zero'. Podese visualizar a logomarca utilizada para apresentar o documento (seis traços representando um conjunto de pessoas em círculo - que podem ser estudantes da 
rede; dois traços representando algum objeto de estudos - possivelmente um livro; tudo considerando as cores da bandeira do Estado). Esta é a mesma logomarca utilizada pelo Estado para apresentar o Currículo Base Educação Infantil e Ensino Fundamental do Território Catarinense (2019).

IMAGEM 1 - Divulgação da consulta pública do 'Marco Zero'

\section{Consulta Pública}

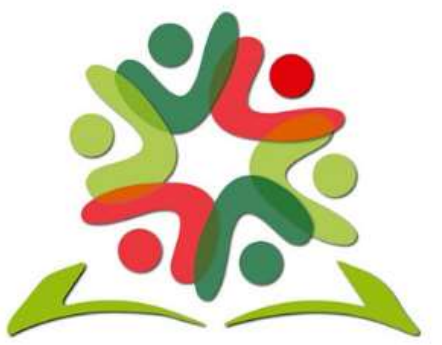

Marco Zero Currículo Base do Território Catarinense para o Ensino Médio

(Fonte: https://www.sed.sc.gov.br/secretaria/imprensa/noticias/30498-comunidade-educacional-podecontribuir-na-elaboracao-do-curriculo-do-territorio-catarinense-para-o-ensino-medio - divulgado em 28/01/2020; consultado em 18/06/2021)

A iniciativa do ofício circular e do convite acima apresentado, era conclamar à participação da sociedade na construção democrática do currículo territorial, deixando um prazo de aproximadamente trinta (30) dias para consulta e acréscimo de sugestões ao documento. Para tal empreendimento, a Secretaria de Estado da Educação, solicitou (cf ofício SED 08/2020) que as direções das escolas dedicassem um tempo da 'Semana Pedagógica' (tempo destinado, antes do início das aulas para os/as professores/as planejarem as ações do ano letivo) do início do semestre daquele ano, para que os professores/as estudassem a proposta e apontassem críticas, sugestões, adendos etc. visando a 'qualificação do material'.

Junto ao ofício (08/2020), seguiu para as escolas um 'roteiro de estudos e atividades referentes à análise do Currículo Base do Território Catarinense (em 
construção)'. Este roteiro indicava que os professores deveriam se reunir por área do conhecimento, ler e analisar os textos, objetos do conhecimento e habilidades propostos no documento 'Marco Zero' e, de acordo com as necessidades, fazer as contribuições para que o documento tomasse a "robustez necessária para depois seguir os trâmites legais, ir ao Conselho Estadual de Educação e, posteriormente, à aprovação" (SECRETARIA DE ESTADO DA EDUCAÇÃO, DIRETORIA DE ENSINO, 2020).

No respectivo roteiro, havia um questionário, produzido para que os/as professores/as de cada área do conhecimento (Linguagens e suas tecnologias; Ciências da Natureza e suas tecnologias; Ciências Humanas sociais e aplicadas; Matemática e suas tecnologias), pudessem analisar o documento e apresentar suas ponderações. Na tangente da área de ciências humanas e suas tecnologias, haviam questões como:

- Utilizando sua experiência em sala de aula e suas leituras, verifique se este quadro dá um bom subsídio para seu planejamento. Caso sinta falta de alguma habilidade, ou objeto do conhecimento, descreva.

- Aponte um link dos conteúdos que auxiliem a aquisição desta habilidade e que envolva as demais áreas do conhecimento.

- [...] tente como exercício, pensar uma situação desencadeadora e a complexidade dos conceitos envolvidos, tanto na área das Ciências Humanas como das demais áreas;

- Os temas transversais abordados no documento contribuem para a construção do projeto de vida dos alunos? De que forma?

- Como as áreas podem articular os conhecimentos por meio de atividades integrativas? (SECRETARIA DE ESTADO DA EDUCAÇÃO DE SANTA CATARINA, DIRETORIA DE ENSINO, 2020)

De acordo com o Parecer número quarenta (40) do Conselho Estadual de Educação de Santa Catarina, o 'Marco Zero' recebeu duas mil cento e vinte (2.120) contribuições de professores/as que estudaram o referido documento e apresentaram seus posicionamentos. Para análise das considerações realizadas, a Secretaria de Educação do Estado, em vinte e oito de janeiro de dois mil e vinte (28/01/2020), publicou uma notícia em seu site afirmando que haveria três seminários com 250 professores da rede de ensino catarinense (SED/SC, 2020 a).

$\mathrm{Na}$ esteira da proposição dos seminários para a discussão e construção do Currículo Base do Ensino Médio do Território Catarinense, a Secretaria de Educação 
do Estado lançou no dia sete (07) de janeiro do ano de dois mil e vinte (2020), o edital número duzentos e oitenta e quatro (284) que tinha como objetivo estabelecer os procedimentos, abrir inscrições sobre o Processo Seletivo Simplificado e fixar normas para a Seleção de profissionais da educação para participação do Ciclo de Seminários para elaboração do Currículo Base do Ensino Médio do Território Catarinense. Este edital tinha como tarefa selecionar duzentos e cinquenta (250) professores/as para dar continuidade à construção do currículo territorial.

Para a organização epistêmica do processo de formação e consolidação do currículo, foi noticiado no site da Secretaria de Estado da Educação que seriam "trabalhadas quatro temáticas relacionadas à consolidação do Currículo Base do Ensino Médio: a) Áreas do Conhecimento - Ensino Médio; b) Percurso Formativo; c) Formação Integral; d) Ensino Médio" (SED/SC, 2020 b). Além dessas temáticas, os/as professores/as estudariam as proposições do 'Marco Zero', observando as contribuições realizadas ao longo da semana de estudos (dos/as professores/as das escolas), possibilitando a finalização do currículo do Ensino Médio do território catarinense.

De acordo com o edital acima citado, os seminários propostos deveriam acontecer na modalidade presencial, para que houvesse participação efetiva dos/as professores/as selecionados. No entanto, no decorrer do ano de dois mil e vinte (2020) tivemos a declaração internacional de pandemia de Covid-19 (Sars-cov-2), que levou para o modo remoto a realização dos seminários.

$\mathrm{Na}$ sequência, faremos um recorte abordando especificamente as questões curriculares que se direcionam para o ensino de filosofia no 'Marco Zero'.

\section{As indicações pedagógicas do 'Marco Zero' e o ensino da Filosofia}

Percebe-se, no documento, um pertinente alinhamento com a Base Nacional Comum Curricular - BNCC (2018) e alguns prelúdios da Proposta Curricular de Santa Catarina - PCSC (2014). Indicando o desenvolvimento de habilidades como ponto central no planejamento e execução das ações pedagógicas desenvolvidas pelos professores. Nesse sentido, a área de ciências humanas e sociais aplicadas, 
indica três procedimentos pedagógicos relativos à mobilização das seguintes habilidades: desnaturalização; estranhamento; sensibilização.

Nessa perspectiva, caberia a área de ciências humanas: instigar a não aceitação (desnaturalização) de alguns aspectos sociais tais como, degradação socioambiental, preconceitos etc.; propondo um processo de estranhamento de situações que afetam a sociedade a fim de exercer um protagonismo na sugestão de hipóteses para resolução de problemas; desenvolvendo um processo de rompimento com atitudes de indiferença (sensibilização) promovendo a percepção atenta das experiências individuais e coletivas (SECRETARIA DE ESTADO DA EDUCAÇÃO DE SANTA CATARINA, MARCO ZERO, L. 22-33) (as referências textuais ao 'Marco Zero' são feitas por linhas, visto que o documento não é paginado).

Assim, o documento situa cada um dos quatro componentes curriculares que compõem a respectiva área, destacando conceitos, procedimentos e inspirações curriculares para cada um deles. 
IMAGEM 2 - Diagrama: Principais conceitos e sua intersecção na Área de Ciências Humanas

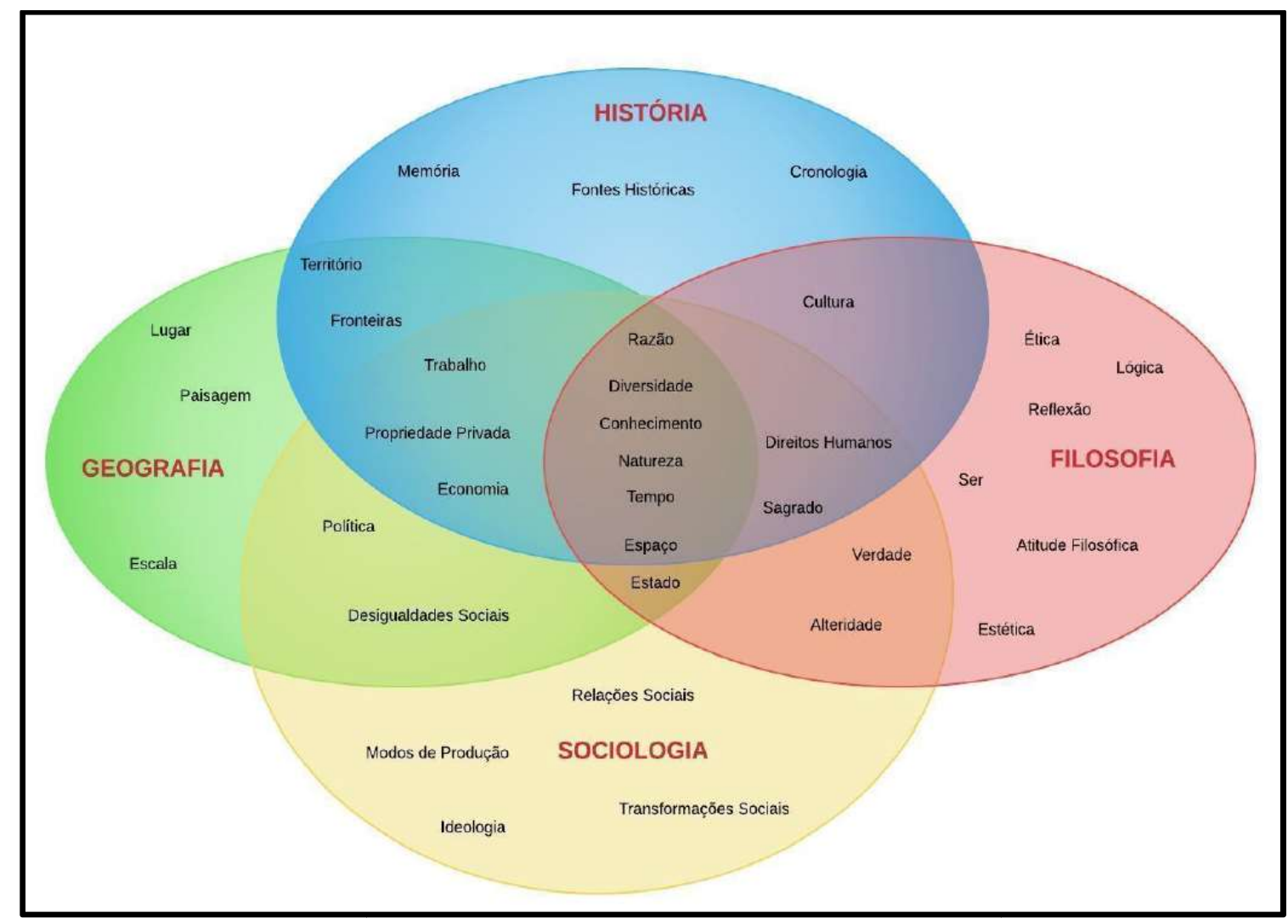

Fonte: SANTA CATARINA. MARCO ZERO DA ÁREA DE CIÊNCIAS HUMANAS APLICADAS PARA

O ENSINO MÉDIO. Disponível em: https://drive.google.com/file/d/1x3O6LrH1CLzrWiwBa5wyN6EhUhXFZJc/view (2020)

$\mathrm{Na}$ imagem acima, podemos perceber que há conceitos que são próprios da filosofia, tais como: ética, lógica, reflexão, ser, atitude filosófica e estética. Há conceitos que estão entrelaçados com a sociologia (verdade e alteridade); a história (cultura); ambas (direitos humanos e sagrado), e também com os três componentes que integram a área: razão, diversidade, conhecimento, natureza, tempo, espaço e Estado. Esse 'diagrama' leva àqueles que o visualizam a perceber a integração conceitual que é possível de estabelecer na área.

Mais do que isso, o diagrama proposto no 'Marco Zero' (imagem 2) leva o seu leitor a refletir sobre a interdisciplinaridade possível na área de ciências humanas sociais e aplicadas para o Ensino Médio (termo utilizado pelo documento). Desse modo, o documento demonstra, através do diagrama, que há interrelações entre os componentes curriculares que compõem a área, mas, também, aponta indícios da 
permanência de especificidades de conteúdo de cada componente que precisava ser mantido. Isso fica evidente quando se visualiza no diagrama de conceitos próprios de cada componente, e os conceitos entrelaçados entre eles.

Olhando para a especificidade da filosofia presente no 'Marco Zero', apresentamos o quadro abaixo, buscando sistematizar algumas indicações pedagógicas e metodológicas para a Filosofia.

QUADRO 1 - Inspirações gerais para Filosofia em Santa Catarina

\begin{tabular}{|c|c|}
\hline L $218-219$ & $\begin{array}{l}\text { O intuito é prepará-los para que tenham um projeto pessoal de vida e para } \\
\text { ser cidadãos responsáveis. }\end{array}$ \\
\hline L $224-225$ & $\begin{array}{l}\text { Ela não é uma disciplina científica, constituindo antes uma atitude e um modo } \\
\text { de reflexão peculiares. }\end{array}$ \\
\hline L 230 & [...] como disciplina que, de algum modo, auxilia todas as outras [...] \\
\hline L $233-234$ & $\begin{array}{l}\text { A compreensão da Filosofia pelos estudantes reforça sua vocação } \\
\text { transdisciplinar. }\end{array}$ \\
\hline L 237 & [...] ajuda desenvolver a habilidade de argumentar. \\
\hline L $238-239$ & [...] auxilia a apreciar e usar essas criações humanas em seu justo valor. \\
\hline L $240-241$ & $\begin{array}{l}\text { [...] estando a filosofia objetivada nos textos dos filósofos, a sua leitura e } \\
\text { discussão constitui um exercício de interpretação da palavra e assimilação } \\
\text { de conceitos [...]. }\end{array}$ \\
\hline L $243-244$ & $\begin{array}{l}\text { Como os filósofos amiúde se ocuparam de questões sociais, pela relação do } \\
\text { homem com o ambiente e pela compreensão da história humana, a Filosofia } \\
\text { tem sempre afinidade com temas trabalhados pela Geografia, História e } \\
\text { Sociologia. }\end{array}$ \\
\hline L $248-250$ & $\begin{array}{l}\text { [...] pretende desenvolver no estudante a capacidade para enfrentar as } \\
\text { questões advindas das mais variadas situações de sua vida lançando mão } \\
\text { do que foi aprendido. }\end{array}$ \\
\hline
\end{tabular}

Fonte: quadro do autor. Sistematizado a partir do documento 'Marco Zero' (SANTA CATARINA, 2020).

É possível perceber (a partir do quadro acima - 1) algumas recorrências pertinentes de serem refletidas: a proposição de que a Filosofia tenha em seu horizonte, principalmente, o desenvolvimento de 'práticas filosóficas' tais como argumentação, análise, interpretação, reflexão, enfrentamento de questões etc., o que estaria apontando para uma maior valorização do filosofar enquanto atitude e 
não da filosofia enquanto conteúdo (história, conceitos, correntes de pensamento, pensadores etc.).

Nessa tangente, o professor Christian Lindberg (2019) nos chama atenção para a reflexão sobre a transformação curricular pela qual a Filosofia é submetida após a reforma do Ensino Médio, passando a ser compreendida como estudos e práticas. Segundo Lindberg (2019), caracterizar a filosofia como estudos e práticas é algo distinto de compreendê-la em uma perspectiva disciplinar, desse modo "uma atividade de protagonismo juvenil, por exemplo, pode ser considerada uma atividade prática de caráter filosófico" (LINDBERG, 2019, s/p). Considerando o exposto no parágrafo e no quadro anterior, podemos nos questionar: estaria o Estado de Santa Catarina propondo que a Filosofia se torne, curricularmente, um conjunto de estudos e práticas em detrimento de seus conteúdos? Em que medida essas inspirações vão afetar o professor no seu dia a dia? Essas e tantas outras questões podem ser realizadas, no entanto só poderemos mensurá-las no decorrer de sua implementação.

Outra questão que nos chama atenção, é o fato de relacionar a aprendizagem da Filosofia com o desenvolvimento da cidadania, algo que já era apontado em outros currículos nacionais e que permanecem nessa proposição. Podemos pensar que essa indicação está fortemente relacionada ao desenvolvimento do protagonismo juvenil, o qual é outra grande tônica da reforma do Ensino Médio.

$\mathrm{Na}$ continuidade dessas 'inspirações gerais para a Filosofia', apresenta-se no 'Marco Zero' um quadro com os objetos do conhecimento e as habilidades a serem desenvolvidas a partir dos objetos. Abaixo (no quadro 2), apresentamos uma seleção dos objetos apresentados para a Filosofia a partir da área de ciências humanas sociais e aplicadas. Para a seleção (realizada a partir de um conjunto de cinquenta e um (51) objetos do conhecimento), utilizamos como critérios os conceitos apresentados no diagrama (imagem 2), observando as inspirações gerais para a Filosofia (quadro 1) com foco nos conteúdos de inspiração filosófica. 


\section{QUADRO 2 - OBJETOS DO CONHECIMENTO}

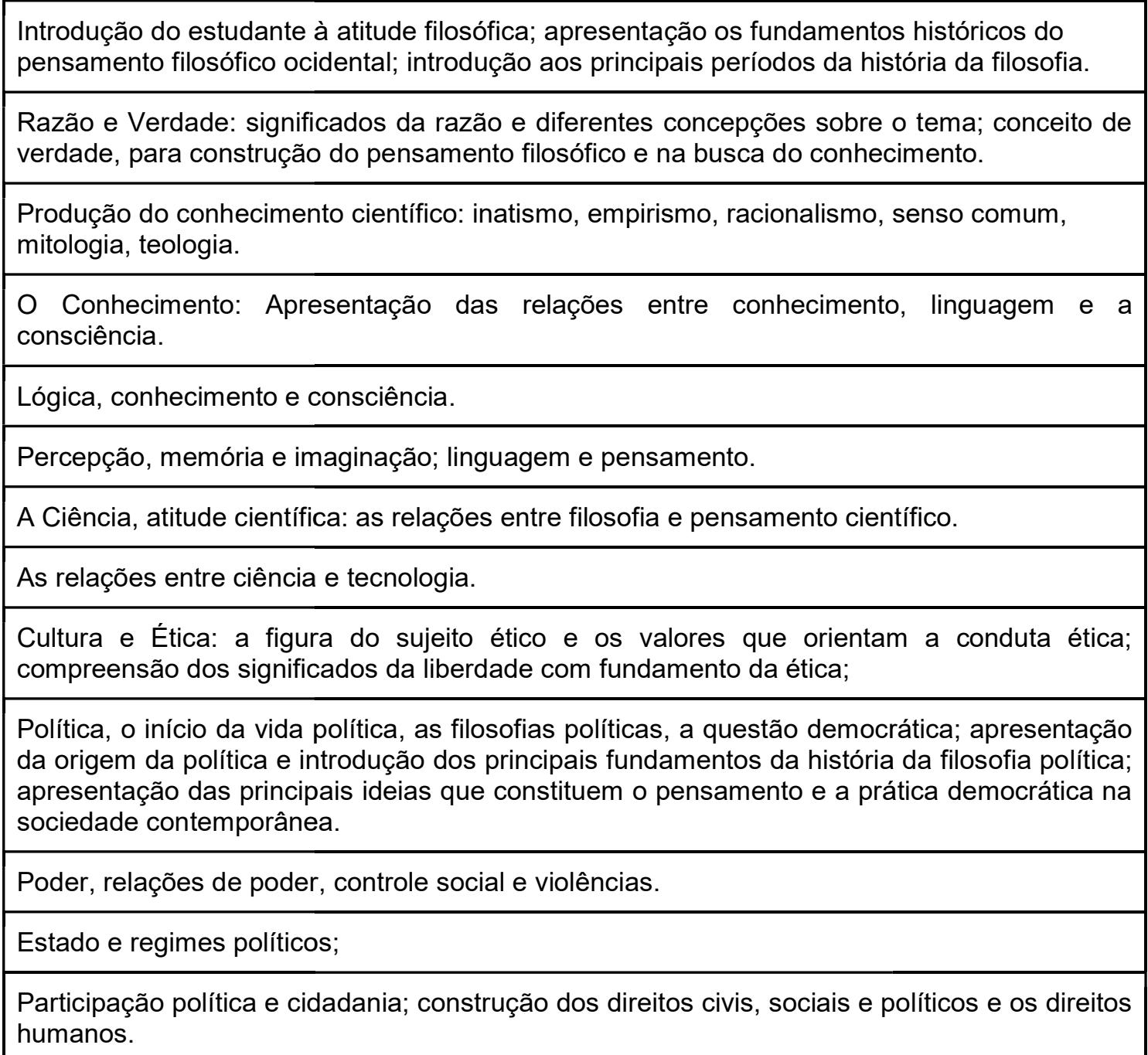

Fonte: quadro do autor. Sistematizado a partir do documento 'Marco Zero' (SANTA CATARINA, 2020).

Pode-se perceber a presença de 'objetos clássicos da filosofia' já apontados em outros currículos do Estado, tais como: política, ética, lógica, história da filosofia etc. (SANTA CATARINA, 1998; 2014). Com esses objetos do conhecimento, podemos perceber que, no 'Marco Zero' havia preocupação com a manutenção da especificidade da Filosofia no currículo escolar da Rede. Assim, é possível vislumbrar a permanência da Filosofia no currículo (ou pelo menos a intenção de mantê-la, visto que o 'Marco Zero' se trata de um documento para consulta pública). 
Mesmo havendo uma preocupação com a manutenção de alguns 'objetos clássicos da filosofia', é preciso lembrar que esse documento do Estado de Santa Catarina, possui inspirações na BNCC, que é o documento nacional. Lindberg (2019) nos desafia a pensar que mesmo diante da manutenção de saberes e objetos da Filosofia na BNCC, estes possuem uma nova configuração pois, (na BNCC) os saberes filosóficos estão diluídos na área denominada de Ciências Humanas e Sociais Aplicadas e "contempla apenas duas áreas da Filosofia: Epistemologia e Ética e Filosofia Política" (LINDBERG, 2019, s/p). Do mesmo modo que na BNCC, no 'Marco Zero', a Filosofia se encontra diluída na área de Ciências Humanas e Sociais Aplicadas e com proposições objetais muito semelhantes, incluindo questões amplas da Filosofia como liberdade, justiça, questões da identidade etc.

Essa problematização nos leva a pensar em outros posicionamentos. Costa (2020) nos afirma que, "quando se restringe o conhecimento historicamente acumulado e conhecimentos ligados ao campo da filosofia [...] se prioriza a formação técnica" (p. 321). Nesse sentido, geralmente, quando se trata de formação técnica (ou alinhamento a um tecnicismo) a formação deixa de lado a criticidade em detrimento de uma formação que seja eficiente e produtiva. Por isso é necessário acompanhar em nossa discussão: estaria a presença da Filosofia nos currículos deixando de lado sua perspectiva de formação da criticidade nos alunos e direcionando sua formação para um modo instrumental de pensar o mundo?

Além disso, percebe-se que as proposições de diálogo interdisciplinar (conforme proposto no Diagrama - imagem 2) também estão presentes nos objetos do conhecimento. Isso é possível afirmar a partir da visualização de objetos que levam em consideração o estudo dos significados da razão; as relações entre a ciência e a filosofia (no que tange às discussões sobre o conhecimento); o estudo dos conceitos de ética e política em suas relações com as diversidades culturais etc. Tudo isso apresentado em perspectivas do conhecimento que se embasam em questões do tempo histórico e do espaço onde os/as filósofos/as produziram seus saberes.

Obviamente que, tendo o 'Marco Zero' como função atualizar o currículo do Estado, alinhando-se à BNCC, propõe-se nele também um conjunto de habilidades a 
serem desenvolvidas. Em seguida, apresentamos (no quadro 3) as habilidades propostas para a área de ciências humanas sociais e aplicadas que se relacionam com a Filosofia, ou minimamente com a atitude filosófica propriamente dita. Entre quarenta e seis (46) habilidades, destacamos oito (8), por possuírem relação mais estreita com os prelúdios filosóficos.

\section{QUADRO 3 - HABILIDADES}

Identificar, analisar e comparar diferentes fontes e narrativas expressas em diversas linguagens, com vistas à compreensão de ideias filosóficas e de processos de produção da realidade histórica, fenômenos geográficos, políticos, econômicos, sociais, ambientais e culturais.

Identificar a influência dos diferentes saberes/tipos de conhecimento na interpretação das realidades e formas de organização social e espacial, problematizando a relação entre indivíduo e sociedade.

Apropriar-se dos diferentes métodos de investigação científica, abrangendo pesquisas quantitativas e qualitativas, de modo a interpretar os fenômenos sociais, históricos, geográficos e filosóficos.

Analisar situações da vida cotidiana, estilos de vida, valores, condutas etc., desnaturalizando e problematizando formas de desigualdade, preconceito, intolerância, discriminação e violências, e identificar ações que promovam os Direitos humanos, a solidariedade e o respeito às diferenças e às liberdades individuais.

Analisar os fundamentos da ética em diferentes culturas, tempos e espaços, identificando processos que contribuem para a formação de sujeitos éticos que valorizem a liberdade, a cooperação, a autonomia, o empreendedorismo, a convivência democrática e a solidariedade.

Compreender a importância do poder, da política e do Estado na organização da sociedade contemporânea, de modo a reconhecer as inter-relações entre eles e suas influências no cotidiano, nas diferentes esferas da vida social.

Compreender a importância da participação social, atuando como cidadãos responsáveis e críticos, percebendo o papel da política na vida pública, discutindo a natureza e as funções do Estado e o papel de diferentes sujeitos e organismos no funcionamento social, analisando experiências políticas à luz de conceitos políticos básicos.

Compreender como o desenvolvimento da democracia influenciou as mudanças na concepção do exercício da cidadania e a institucionalização dos direitos humanos, identificando estes como conquistas historicamente construídas, suas limitações e incompletudes, reconhecendo a participação política como imprescindível para sua ampliação.

Fonte: quadro do autor. Sistematizado a partir do documento 'Marco Zero' (SANTA CATARINA, 2020). 
Discutir epistemologicamente o papel das habilidades em um currículo é algo que foge ao escopo deste trabalho. No entanto, é válido ressaltar que essas habilidades, apresentadas no quadro acima, levam em consideração o domínio de conhecimentos específicos para que possa se desenvolver. Chamo atenção para os verbos que demonstram as ações no início de cada uma delas: identificar; apropriarse; analisar e compreender; são ações que pressupõe estudo específico dos conceitos e conteúdos que sustentam a filosofia, para que o estudante possa desenvolver as ações prescritas.

Assim como a BNCC reassumiu um modelo educacional embasado em competências, o currículo de Santa Catarina, proposto no 'Marco Zero', também o assumiu. Assim, “as disciplinas consideradas 'demasiado teóricas' devem, segundo a ótica dos reformadores, ceder espaço às competências e habilidades práticas em vista de adequação imediata ao mundo do trabalho" (FÁVERO, CENTENARO, SANTOS, 2020, p. 6). Essa é uma constatação muito pertinente de ser realizada, pois destaca ainda mais a relação e o alinhamento entre a Reforma do Ensino Médio, a BNCC e 'Marco Zero'.

Essa perspectiva curricular se alinha, nas palavras de Lindberg (2019) a uma concepção neotecnicista "[...] compreendida como aquela que capacita os estudantes, única e exclusivamente, ao manuseio dos conhecimentos que lhe são dados". Nesse sentido "[...] o caráter crítico e criativo que a educação pode permitir aos indivíduos é totalmente podado, tornando-os apenas em sujeitos que operam funções previamente determinadas por outrem" (LINDBERG, 2019, s/p). Assim, seguimos afirmando que é necessária uma cuidadosa atenção aos processos de desdobramentos curriculares, para que possamos constatar na prática esse alinhamento tecnicista e instrumental do currículo.

\section{Considerações finais}

Pode-se considerar que nosso objetivo central foi atingido, percebendo que foi possível sistematizar os prelúdios da permanência da Filosofia no 'Marco Zero' do currículo do Ensino Médio, proposto após a reforma dessa etapa da educação. É 
importante afirmar que foi possível perceber continuidades da Filosofia no Estado, levando em consideração o que é lido no documento em questão. Obviamente que a história curricular do componente foi se alterando, conforme citamos brevemente em alguns documentos de outros tempos (levando em consideração outras construções curriculares do Estado).

O pesquisador catarinense Juares da Silva Thiesen (2021, p. 6), faz algumas considerações relevantes acerca do processo que se desenvolve no Estado de Santa Catarina:

\begin{abstract}
A recontextualização da BNCC no território catarinense, na medida que reafirma conceitos de racionalidade instrumental contidos no documento nacional, promove certo apagamento dos princípios e fundamentos construídos durante quase 30 anos de produção e discussão da chamada Proposta Curricular de Santa Catarina, um trabalho coletivo dos profissionais da educação do Estado edificado sobre outra perspectiva teórica, que vai sendo silenciado para ganhar voz rarefeitos fundamentos do texto Currículo Base. [...] Ainda que o grupo de formuladores do documento Currículo Base do Território Catarinense tenha feito algum esforço para acolher certos conceitos da Proposta Curricular de Santa Catarina, a reprodução no documento do Estado, de um conjunto de competências e habilidades propostas na BNCC nacional, mantendo-se a mesma lógica de prescrição para as trajetórias formativas na Educação Básica, representa uma perda considerável em termos de autonomia curricular para as redes de ensino.
\end{abstract}

Ou seja, as proposições curriculares do Estado de Santa Catarina (no que tange o Ensino Médio, após a reforma nacional), alinham-se par e passo ao que é proposto na BNCC. Isso apresenta alguns riscos à autonomia que o Estado possuía em relação a sua história da Proposta Curricular de Santa Catarina. Percebe-se, assim, que o Estado vai operar pelo menos de acordo com o que é proposto (e o que pudemos ler para construir esse texto) na mesma lógica nacional, embora o documento aponte para a presença de componentes curriculares como a Filosofia.

Cabe ainda, nessas considerações ressaltar que, no dia nove (09) de março de dois mil e vinte e um (2021) o Conselho Estadual de Educação emitiu o parecer número quarenta (40), aprovando o Currículo Base do Ensino Médio do Território Catarinense. E na data de vinte e três (23) de julho do ano de dois mil e vinte um (2021), o documento foi disponibilizado em modo digital para as escolas de Santa Catarina. Um aprofundamento desse documento foge o escopo deste artigo, porém, 
pode-se afirmar que houveram mudanças significativas na área e na tangente da Filosofia.

\section{Referências}

BRASIL. Lei 13.415 de 16 de fevereiro de 2017. Brasília: Presidência da República: 2017. Disponível em: http://www.planalto.gov.br/ccivil_03/_ato2015-

2018/2017/lei/l13415.htm. Acesso em 17/08/2021.

BRASIL. Ministério da Educação. Base Nacional Comum Curricular. Brasília, 2018. Disponível em:

http://basenacionalcomum.mec.gov.br/images/BNCC_EI_EF_110518_versaofinal_sit e.pdf. Acesso em: 17/08/2021.

COSTA. Regis. O ensino de Filosofia no Brasil e o contexto da reforma do ensino médio brasileiro em 2016. Cadernos PET de Filosofia. V. 18, n. 2, agosto de 2020. ISSN: 1517-5529. Disponível em: https://revistas.ufpr.br/petfilo/article/view/66875.

FÁVERO, Altair Aberto; CENTENARO, Junior Bufon; SANTOS, Antonio Pereira dos. Reformas curriculares e o ataque ao pensamento reflexivo: o sutil desaparecimento da filosofia no currículo da Educação Básica no Brasil. Revista digital de ensino de filosofia. V. 6, n.1, 2020. ISSN: 2448-0657. Disponível em: https://periodicos.ufsm.br/refilo/article/view/42599

LINDBERG, Christian. O ensino de filosofia e a reforma educacional: o que fazer? 2020. Disponível em: http://anpof.org/portal/index.php/en/comunidade/colunaanpof/2052-o-ensino-de-filosofia-e-a-reforma-educacional-o-que-fazer.

SANTA CATARINA. Secretaria de Estado da Educação. Proposta Curricular de Santa Catarina: educação infantil, ensino fundamental e médio (formação docente para a educação infantil e séries iniciais). Florianópolis: COGEN, 1998.

SANTA CATARINA. Secretaria de Estado da Educação. Proposta Curricular de Santa Catarina: Formação Integral na Educação Básica. Florianópolis: Secretaria de Estado da Educação: 2014.

SANTA CATARINA. Secretaria de Estado da Educação. Caderno de orientações para a implementação do Novo Ensino Médio. Florianópolis: Editora Secco, 2019 a.

SANTA CATARINA. Secretaria de Estado da educação. Currículo Base da Educação Infantil e do Ensino Fundamental do Território Catarinense. Florianópolis: Secretaria de Estado da Educação, 2019. 
SECRETARIA DE ESTADO DA EDUCAÇÃO DE SANTA CATARINA. Ofício Circular $n^{\circ}$ 08/2020. Florianópolis, 27 de Janeiro de 2020. Disponível em: https://drive.google.com/file/d/1zYUdbQzTEexstSqpblqFliOtGVqls6Kd/view?usp=sha ring.

SECRETARIA DE ESTADO DA EDUCAÇÃO DE SANTA CATARINA. Marco Zero do Currículo do Currículo Base do Ensino Médio do Território Catarinense. Florianópolis, Janeiro de 2020. Disponível em: https://drive.google.com/file/d/1x306LrH1CLzrWiwBa5-wyN6EhUhXFzJc/view.

SECRETARIA DE ESTADO DA EDUCAÇÃO DE SANTA CATARINA. DIRETORIA DE ENSINO. Roteiro de estudo e atividades do Currículo Base do Ensino Médio do Território Catarinense (em construção). Florianópolis, Janeiro de 2020. Disponível em:

https://drive.google.com/file/d/1Aw6G3GLVVFtBtrPqtbDIXgj0oHgowq23/view?usp=s haring.

SECRETARIA DE ESTADO DA EDUCAÇÃO DE SANTA CATARINA (SED/SC). Comunidade Educacional pode contribuir na elaboração do currículo do território catarinense para o ensino médio. 28 Janeiro 2020 a. Disponível em: https://www.sed.sc.gov.br/secretaria/imprensa/noticias/30498-comunidadeeducacional-pode-contribuir-na-elaboracao-do-curriculo-do-territorio-catarinensepara-o-ensino-medio. Acesso em 18/06/2021.

SECRETARIA DE ESTADO DA EDUCAÇÃO DE SANTA CATARINA (SED/SC). SED seleciona profissionais que atuarão em seminários do currículo do ensino médio. 07 de fevereiro de 2020 b. Disponível em:

https://www.sed.sc.gov.br/secretaria/imprensa/noticias/30508-sed-selecionaprofissionais-que-atuarao-em-seminarios-do-curriculo-do-ensino-medio. Acesso em 18/06/2021.

SANTA CATARINA. Edital, № 284 de 07 de janeiro de 2020. [Processo Seletivo Simplificado Seminários BNCC do Ensino Médio]. Santa Catarina: órgão oficial do Estado. Florianópolis, janeiro de 2020. Disponível em:

https://www.sed.sc.gov.br/secretaria/imprensa/noticias/30508-sed-selecionaprofissionais-que-atuarao-em-seminarios-do-curriculo-do-ensino-medio. Acesso em: 18/06/2021.

SANTA CATARINA. CONSELHO ESTADUAL DE EDUCAÇÃO. COMISSÃO DE EDUCAÇÃO BÁSICA. Parecer CEE/SC 04/2021. Florianópolis, 09/03/2021.

Disponível em: http://www.cee.sc.gov.br/index.php/legislacao-downloads/educacaobasica/jovens-e-adultos/educacao-basica-jovens-e-adultos-pareceres/pareceres-10. Acesso em: 17/08/2021. 
SILVA, Filomena Lucia Gossler Rodrigo da; MARTINI, Tatiane Aparecida; POSSAMAI, Tamiris. A Reforma do Ensino Médio em Santa Catarina, um percurso atravessado pelos interesses do empresariado. Trabalho Necessário. V. 19, n. 29, 2021. ISSN. 1808-799X. Disponível em:

https://periodicos.uff.br/trabalhonecessario/article/view/47398. Acesso em 17/08/2021. DOI: https://doi.org/10.22409/tn.v19i39.47398.

THIESEN, Juares da Silva. Políticas Curriculares de Educação Básica: recontextualização da BNCC no território de Santa Catarina. Revista Espaço do Currículo. V. 14, n. 1, 2021. ISSN. 1983-1579. Disponível em:

https://periodicos.ufpb.br/ojs/index.php/rec/article/view/56496. Acesso em: 17/08/2021. DOI: https://doi.org/10.22478/ufpb.1983-1579.2021v14n1.56496.

\section{(c) (1) (8)(2)}

This work is licensed under a Creative Commons Attribution-NonCommercial 4.0 International (CC BY-NC 4.0) 